\title{
Effect of Waste Glass Powder on the Swelling and Strength Characteristic of Karak Expansive Clay
}

\author{
Bakht Zamin ${ }^{1}$, Hassan Nasir ${ }^{2}$, Asim Farooq ${ }^{3}$, Beenish Jehan ${ }^{1}$, and Muhammad Tariq Bashir ${ }^{1}$ \\ ${ }^{I}$ Department of Civil Engineering, CECOS University of IT \& Emerging Sciences, Peshawar, Pakistan \\ ${ }^{2}$ Water \& Sanitation Services, Peshawar (WSSP), Pakistan \\ ${ }^{3}$ Pak-Austria Fachhochschule: Institute of Applied Sciences \& Technology, (PAF-IAST), Pakistan \\ Correspondence Author: Bakht Zamin (bakht@cecos.edu.pk)
}

Received July 15, 2021; Revised October 05, 2021; Accepted October 21, 2021

\begin{abstract}
Expansive soils are generally considered problematic due to undesirable geotechnical characteristics like expansion, shrinking, settlement, and heaving. Such soils have low shear strength which decreases after moistening or other physiological aggravations. Subsequently, such soils need proper improvement before constructing a structure. Different industrial wastes have been used for the stabilization of weak soil in the past. In the current investigation, the impact of Waste Glass Powder or WGP, on the strength and swelling characteristics of swelling soils has been assessed. The primary target of this examination was to explore the utilization of WGP in geotechnical applications for controlling the settlement and expanding qualities. For this reason, the local expansive soil of district Karak, Pakistan was selected and their engineering properties were assessed. The experimental work consists of conducting the consistency limits, California Bearing Ratio (CBR), specific gravity, standard Procter tests, and I-D swelling. These tests were carried out on both natural as well as on modified specimens. For modification purposes, WGP was added in different proportions with the incremental rate of $4 \%$, for instant $0 \%, 4 \%, 8 \%, 12 \%, 16 \%$, and $20 \%$. The addition of waste glass powder greatly diminished the swelling properties of the tested soil and also improved the engineering characteristics. A maximum reduction in swelling was observed at $20 \%$ addition of WGP. Similarly, the liquid limit was also reduced, and the specific gravity and Maximum Dry Unit Weight (MDD) increased by adding the optimal content of WGP.
\end{abstract}

Index Terms: Expansive Soil, Waste Glass Powder, California Bearing Ratio, I-D Swelling, Maximum Dry Unit Weight.

\section{INTRODUCTION}

Expansive soils are also known as swell-shrink soils, active clay, or calamitous soils. swelling soil is ordinary soil that goes through gigantic volume changes subsequent to changing the water content, for example, because of rainwater. The volume change occurs due to the presence of expandable minerals belonging to montmorillonite and smectite groups [1]. These minerals have an affinity to assimilate water in their layers and expand or swell. Expansive soil is distributed worldwide particularly in arid and semi-arid zones where the annual rainfall is less than the evapotranspiration. The growing of clayey minerals is mostly connected with three fundamental boundaries: the topography of the area, geotechnical characteristic of the soils, and the natural environmental conditions of the region. [2-4]. The major cause of failures of structures is due to variation of moisture conditions in these soils. Significant reasons for moisture fluctuation are intense rain, floods, and leakages caused in the water supply or sewer pipes lines [5] and [6]. Expansive soils are considered a potential natural hazard and have caused severe distresses to various civil engineering structures not only in Pakistan but also throughout the world. The distress and damage to infrastructure in Oman in worth focusing on, which is expected because of ignoring of issues/problems associated with expansive soils during the planning and development stage [7].

Swelling soils occur in those regions where repeated periods of rainfall and drought are observed. In Asia, the types of expansive soils depend upon shale, montmorillonite content, and calcareous material and their distribution that is a function of geology, sedimentation, and climate impact. The arid climate and severe weathering conditions intensify the presence of such soils [8]. In Pakistan swelling clay of low and high plasticity are also reported in the Karak, Bunnu, Kohat, DI Khan, and Jhelum areas [9]. The presence of expansive soils can be assumed from several visual indicators like desiccation cracks on the natural surface ground, diagonal crack, and sinking of lightly loaded structures in the surrounding areas. Such soils are moisture-sensitive, having low inherent shear strength and greater dry density [10]. When these soils are subjected to moisture fluctuation, a great change in volume takes place. As the soils in the deep layers are confined due to the overburden pressure of soil, subsequently, the fluctuation is severe in the shallow layers i.e, the top few meter depth ( $1 \mathrm{~m}$ to $3 \mathrm{~m}$ ).

The expansion in the volume of soil causes because moisture gained is diverted into an upward moment of soil. As a result, the structure constructed on such soil fails because of the repeated swelling and heaving up. The extent of swelling is controlled by cation exchange 
capacity, layers bonding, and charge on the surface of clayey minerals and basic mineral composition [11]. Besides this, the surface area also plays an imperative role in the swelling and shrinkage of expansive soils. The soil characteristics are improved due to cation exchange, which is an effective and desirable reaction as well as an important indicator of changes in the mineralogy of treated soils [12]. The expansion and shrinkage of expansive soils is the response of expansive soils when water gets inside, and therefore lightly loaded structures may encounter settlement and/or heaving [13]. Swelling and shrinkage of expansive soil causes heaving upward and settlements of light building foundations. Sometimes severe cracking appeared in the weak zones of such buildings. Severe distresses can be observed in pavements, slopes, and reservoirs lining constructed on swelling soils. The range of swell pressure is of the order 30 tone $/ \mathrm{m}^{2}$ to 150 tones $/ \mathrm{m}^{2}$ while the heaving value is $10 \mathrm{~cm} 30 \mathrm{~cm}$ for expansive soils deposits in the area [14]. The study of expansive soil is important because reports showed that in the United States alone, the harm brought about by contracting and expanding soils add up to about $\$ 10$ billion every year, which is more noteworthy than the joined harms from catastrophic events like floods, storms, seismic tremors, and twisters tornadoes [15]. Focusing on the proposed damages of the expansive soils, it is obligatory to stabilize the expansive soils before constructing a structure on them.

Several methods have been reported for the stabilizations of expansive soils including chemical additions, prewetting, moisture control system, and thermal methods [16]. There are some limitations associated with each of these mentioned methods. Sometimes special design techniques are also utilized to protect the structures from distress. Besides this excavate-and-replace and modifications of geotechnical properties have been practiced to combat expansive soils. The third option that is being frequently focused upon nowadays is adding various additives such as lime, cement, marble dust, glass powder, and rice husk, etc., [17]. In Pakistan, there are millions of tons of waste glass produced, which needs to be properly utilized. The current investigation aims to utilize this wasted glass for the stabilization of local expansive soils.

\section{BACKGROUND LITERATURE}

The engineering characteristics of expansive soils in Pakistan were evaluated by researching in the Punjab and Khyber Pakhtunkhwa (KPK) provinces of Pakistan [18]. Expansive soils are considered a natural hazard especially for light structures if not effectively stabilized. Such structures include residential buildings, pavements, etc. Many additives like lime $(\mathrm{CaO})$, Ordinary Portland Cement (OPC), gypsum, fly ash, agricultural wastes, and industrial wastes, have been used for the modification of expansive soils in recent years by different investigators [19]. Furthermore, the environmental and financial advantages of utilizing waste materials have remarkable properties for some geotechnical applications [20]. It is tracked down that fly ash, lime, cement, and materials containing calcium chloride are very useful additives and have essentially improved the engineering characteristic of weak and problematic soils [21]. An author Qureshi and his associates in 2006 investigated the effect of lime, OPC, and fly ash on the swelling behavior of Dera Ismail Khan (D.I Khan) expansive soils. This investigation concludes that lime is a more effective modifier than OPC. Lime is an effective stabilizer of expansive soils that is treacherous due to the high potential of volume change [22]. When treated with lime, the properties of clayey materials are changed abruptly. As the cohesion is reduced and granular nature dominates, there is an overall improvement in the mechanical properties of swelling soils [23]. The concepts of special foundations including various piers and moisture barriers are a few innovative approaches to cater to expansive clays [24]. The physiochemical mechanisms involve; cation exchange reaction, dissociation, Pozzolonic process, and cementitious process that mainly governs the soil-lime reactions i.e., improvement in the geotechnical properties. Marble dust was employed in the problematic red tropical soil and author Okagbue and associates observed significant improvement [25]. In the recent past, tremendous research has been carried out for expansive soil stabilization by industrial and agricultural waste materials. The inevitable use of expansive soil is coupled with their prevalence. Large shrinkage cracks in expansive soils are causing substantial damage to roads, buildings, and various underground utilities of the Karak region as evident in Figures 1.

The current study was based on the addition of varying proportions of WGP for the stabilization of stabilizing Karak expansive soils to evaluate the effectiveness of WGP or otherwise in improving the plasticity, swell potential, and strength characteristics. These stabilizing materials are economical and locally available in the region. The primary reason for selecting the glass powder is the presence of silica (70 \%) and lime (10\%) in WGP. Simultaneously, the glass powder is pozzolanic and can be used to modify $\mathrm{SO}^{4}$ - rich expansive soil. The presence of silica makes it a good pozzolanic material in developing cementitious properties in concrete and clayey materials. Similarly, the presence of lime gives some extra strength to weak soil if hydrated. Materials like WGP containing lime or $\mathrm{CaO}$ make it suitable for use following the wellknown traditional additive i.e., lime. The Karak expansive soils have damaged various structures and represent a serious issue in the area with articulated wet and dry conditions. The yearly pattern of wetting and drying makes soils psychologist and swell every year. Thusly, the parched areas of the nation are substantially more helpless to harm from broad soils than locales that keep up with sodden soil conditions reliably.

Soil adjustment is a method to improve the geotechnical attributes of poor clayey soils by changing their properties. Because of quick development in the development business, a great deal of waste material is being produced each day which represents the issue of its removal [26]. Assuming the delivered squander glass is used for soil adjustment, it will alleviate the issues of its removal dependent to some degree.

The key objective of the study was to assess WSP as a stabilizing agent to enhance the geotechnical characteristics of local expansive soils. The most critical manner by which swelling soils can distress the foundations is heaving when such soils expand upon saturation. Expansive soils lift and break lightly loaded 
structures, line strip foundations, also, regularly cause trouble in-slab floor and boundary walls. Glass powder is extremely sluggish and also non-biodegradable. It degrades like normal natural rock. As an inactive construction material, it can diminish the shrink-swell behavior of expansive soil.

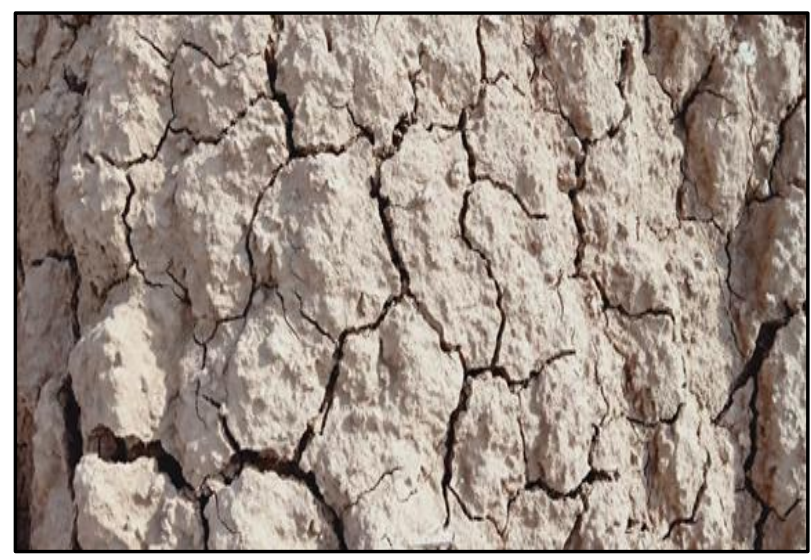

(a)

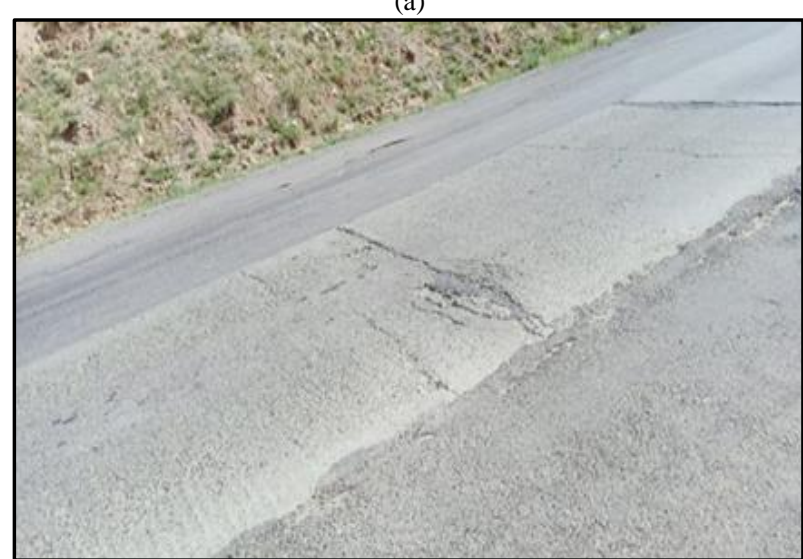

(b)

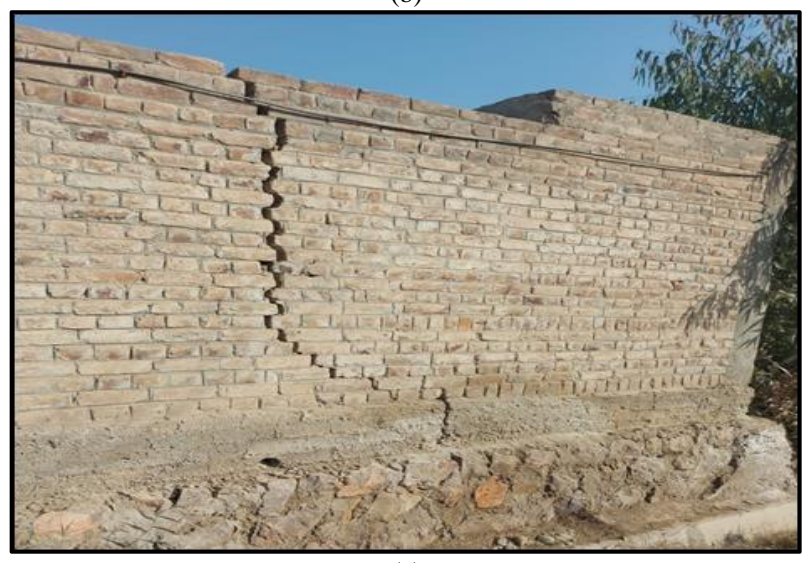

(c)

Figure 1: (a) Indicators of Expansive Soil in Karak, (b) Settlement in Main Highway, (c) Cracks in the Boundary Wall of a Building

The dual aim was to improve the properties of expansive soil and reduce environmental problems currently being encountered. From the standpoint of diminishing the tendency of swelling or shrinkage and ameliorating the mechanical properties, the stabilization of swelling soils is considered. It is indicated from the literature that there is insignificant exploration available on stabilizing expansive clays in the Karak region of Pakistan.
This research is carried out to add to the literature in the same area. Based on stated pieces of evidence it is needed to investigate the Karak expansive soils and propose some recommendations for its stabilizations. To cover the gap in the existing literature a detailed experimental study was therefore undertaken.

\section{INVESTIGATED MATERIALS AND PROCESSING}

For exploratory work, the specimens of expansive clay were acquired from the Karak site. It is situated in the southern piece of Khyber Pakhtunkhwa (KPK). The yearly precipitation of this space is around $844 \mathrm{~mm}$. Distributed samples of the swelling soil were gathered from 'Ammberi Town' close to the fundamental Karak expressway. For test assortment, the open channel technique was incorporated. The coordinates of the spot in Karak are: $33^{\circ} 33^{\prime} 10.8^{\prime \prime} \mathrm{N}$ and $71^{\circ} 25^{\prime} 44.4^{\prime \prime} \mathrm{E} 33^{\circ} 6^{\prime} 2^{\prime \prime}$ North and located at Latitude: 33.100811 Longitude: 71.082531 as mentioned in Figure 2 below.
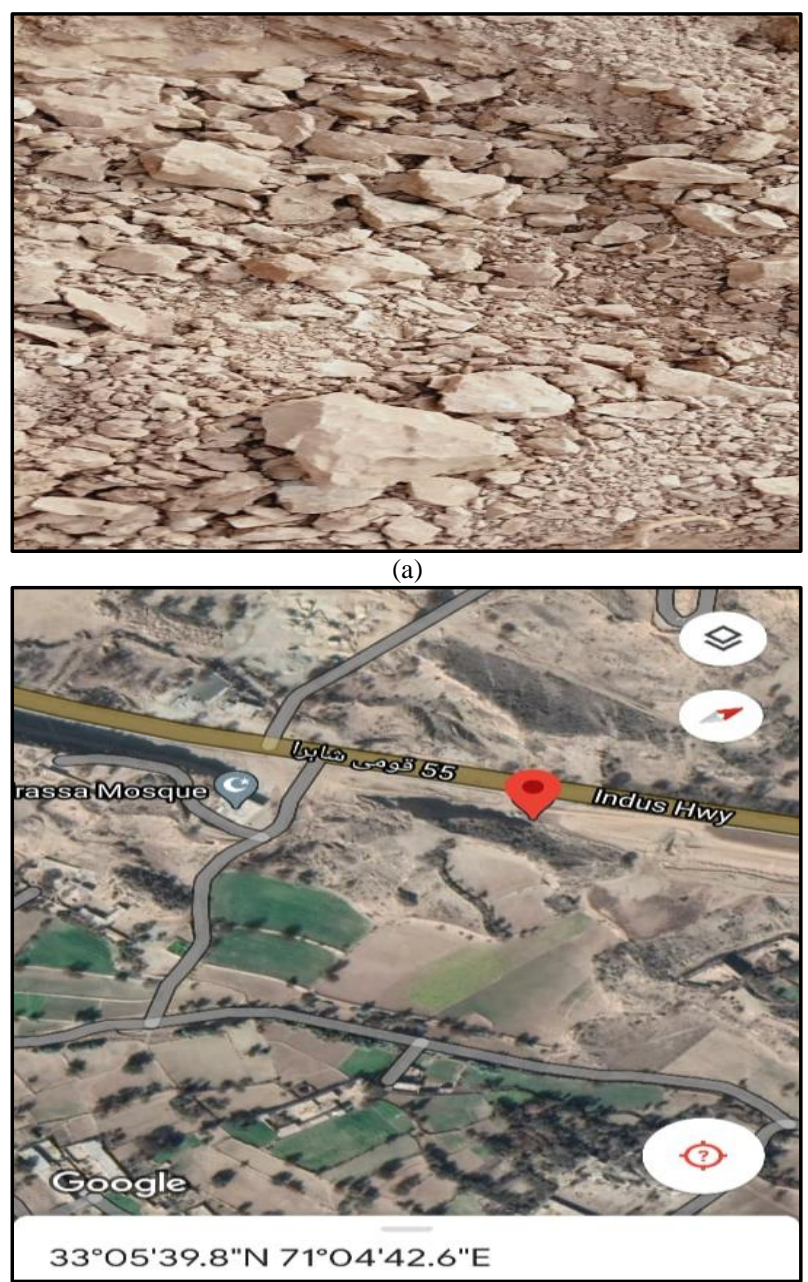

(b)

Figure 2: (a) Site of the Karak Expansive Soil Selected (b) Details of Location

The color of clay is reddish-brown and very stiff in dry form. The representative samples were taken from the surface, at 2 feet, 4 feet, and 6 feet depths. The weight of each sample was about 20 kilograms. After collection, samples were packed properly in polythene bags to 
protect the evaporation of moisture from the samples. Samples shifted to the geotechnical laboratory for testing the basic engineering properties. After finding the natural moisture, the sample was blended in the 'Los Angelus Abrasion' machine to get the pulverized samples.

Another material used in this study was Waste Glass Powder or WGP. Squander glass was taken from the 'Rehman Glass Plant' in industrial zone Hayatabad Peshawar. The glass processing plant at phase 3 indirect, Hayatabad Peshawar. The waste glass was crushed in the ball mill (processing plant) at the Pakistan Council of Scientific \& Industrial Research (PCSIR) lab. Squander glass was transformed into a cinder with the assistance of Ball Mill Apparatus. The waste glass was so ground that it passed over strainer \#200 passing and the particular gravity was observed to be 2.56 .

\section{APPLICATION FROM FIELD PERSPECTIVE}

Legitimate plans and testing are significant parts of any modification method. Research facility tests and in-situ tests can build up legitimate plan standards while deciding the suitable rate for the expansion of any added substance for accomplishing the ideal designing properties. Modification of the soil is done so that the balancing out material WGP is pre-spread onto or blended into the materials which should be settled. Mechanical rotors are used for processing and blending purposes as displayed in Figure 3, underneath.

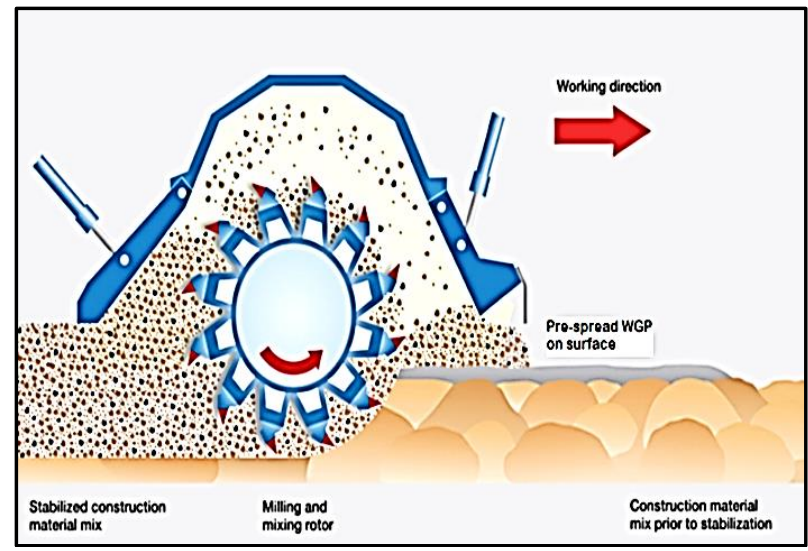

Figure 3: Schematic view of placing and mixing of WGP for Weak Subgrade Soil Adopted from Cortellazzo and Cola

Conventionally, the added substances are blended into the dirt until the desired properties are accomplished. Then, at that point, the establishment of street materials is put on the balanced-out surface. This cycle can shift contingent upon the normal properties of parent soils or materials and the sort of added substance used. Besides, it ought to be noticed that the presence of sulfates, sulfides, carbon dioxide, and natural substances in the balancing out materials can add to startling or unwanted properties of the treated soil [27-29].

\section{RESEARCH METHODOLOGY}

The experimental work of this research study consist of adding the WGP in the expansive clay of District Karak, Pakistan. The percentage of WGP used was 4, 8, 12, 16, and 20. Design dose of WGP was added in oven-dried soil specimens and mixed thoroughly for a reasonable time for getting a uniform mixture. After adding the glass powder the swelling percentage, specific gravity, CBR variations, compaction tests, and liquid limit tests were conducted. These tests were also performed for control specimens as well. All the tests were performed by the most recent ASTM principles. For I-D expanding the ASTM D-4546 testing technique was followed. As per this strategy, a stove-dried example went through a 425 micron strainer was used for test manufacture. Specimens were prepared at Most Extreme Dry Density (MDD) by adding the predefined amount of water and WGP to the dry soil and blended absolutely until a mix of uniform consistency was accomplished. The blend was saved for water homogenization for around 24-48 hours by putting away it in a fixed impenetrable zip lock cover.

The developed specimens were then compacted in the oedometer ring at the compaction condition of dry unit weight at ideal dampness content. Wet filter papers were put on one or the other side of the specimen to shield it from direct contact with water. Pre-soaked permeable stones were additionally positioned on the top and lower part of the ring. In the wake of embedding the ring in the oedometer cell, an extra charge of one $\mathrm{kPa}$ (seating load) was set on the sample. The underlying twisting underneath the seating load was noted and furthermore, the dial measure was set to zero for the underlying stature. The cell was then immersed in water in this way, allowing the soil specimen to enlarge uninhibitedly inside the upward heading. The deformation ' $\Delta \mathrm{h}$ ' was noted until the primary swell was completed.

The test results clearly showed the variation of One Dimensional (I-D) swell and other fundamental properties on the addition of WGP.

\section{DESCRIPTION OF RESULT}

The experimental work of this investigation was comprised of sieve analysis, liquid limit, I-D swell percentage, specific gravity, CBR variations, and standard Proctor tests. The results are shown in the following section.

The basic engineering properties for the control sample are listed in Table 1 below. The Grain Size Distribution (GSD) curve has also appeared in Figure 4. This curve showed that the Karak soil contains $28 \%$ sand, $44 \%$ silt, and $28 \%$ of clay. It was also noted from the GSD curve that gravel size particles are missing in the investigated Karak expansive soil.

Table 1: Physical Properties of Karak Expansive Clay for the Control Sample

\begin{tabular}{|l|c|c|}
\hline \multicolumn{1}{|c|}{ Properties } & Value & Related Standard \\
\hline $\begin{array}{l}\text { Max. Dry Unit Weight } \\
{[\mathrm{kN} / \mathrm{m} 3]}\end{array}$ & 18.5 & ASTM D698-07 \\
\hline OMC [\%] & 17.8 & ASTM D2216-19 \\
\hline Liquid Limit, [\%] & 52.5 & ASTM D4318-10 \\
\hline The Plastic Limit, [\%] & 18.0 & ASTM D4318-10 \\
\hline Plasticity Index, [\%] & 34.0 & ASTM D4318-10 \\
\hline Specific Gravity & 2.56 & ASTM D5550-06 \\
\hline
\end{tabular}




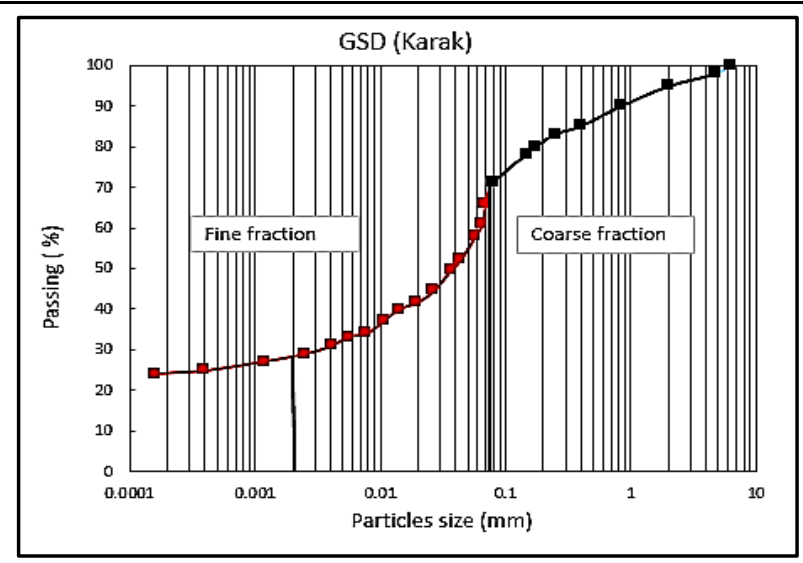

Figure 4: Grain Size Distribution (GSD) Curve of Karak's Expansive Clay

Based on plasticity index and gradation results the investigated soil is classified as clay with a high liquid limit (greater than $50 \%$ ). So the soil belongs to the $\mathrm{CH}$ group of soil under the Unified Soil Classification System USCS).

\section{A. Effect on Compaction and Moisture Content}

Figure 5 shows the variations of moisture content and Maximum Dry Density (MDD) of the tested soil after adding the glass powder. It is clear from Figure 5, the MDD changes from $1.89 \mathrm{~g} / \mathrm{cm}^{3}$ to $2.2 \mathrm{~g} / \mathrm{cm}^{3}$. Although this increase/improvement is not noticeable up to the mark. However, if we consider the reduction of the moisture content that occurs for saturation during the compaction process then a significant amount of the Moisture Content (OMC) was reduced. The OMC required for achieving the maximum density for control samples was $17.8 \%$. After adding glass powder, the moisture requirement gradually reduced and reached 13.5 $\%$ for $20 \%$ addition of WGP. This reduction of moisture is probably due to the filling up of the voids in soil by fine glass powder or by replacing the clayey friction from the mixture. Moisture content is drastically changed by adding the WGP in 8 20\%. Therefore the WGP addition in this percentage can be beneficially utilized for construction purposes on expansive soils in the Karak areas.

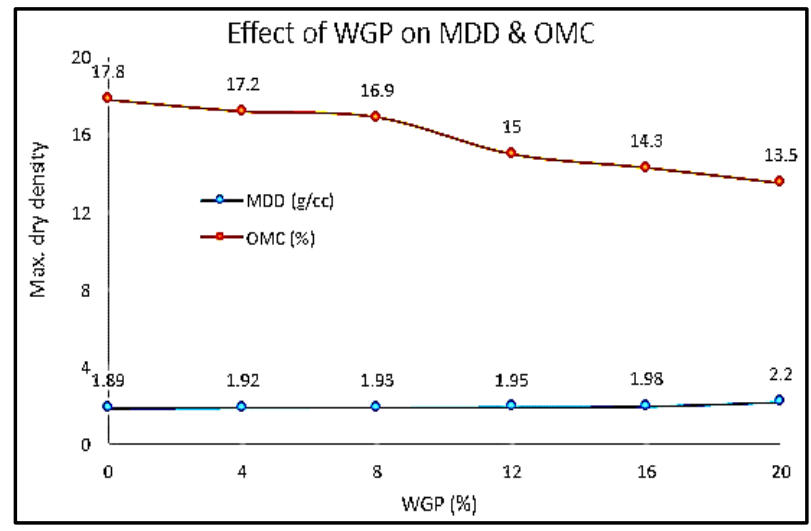

Figure 5: Fluctuation of OMC and MDD on the Addition of WGP

\section{B. Effect of WGP on Specific Gravity}

The variation of specific gravity on the addition of WGP is shown in Figure 6. It is well clear that the specific gravity of expansive soil increased from a value of 2.56 (controlled specimen) to a maximum value of 2.69 . The reason behind this is the dense nature of WGP. It is clear from the literature that the specific gravity of clear and colored WGP is about 3.02. This high specific gravity is due to the least particle size. So due to the high specific gravity of glass powder, the overall weight of the system increased.

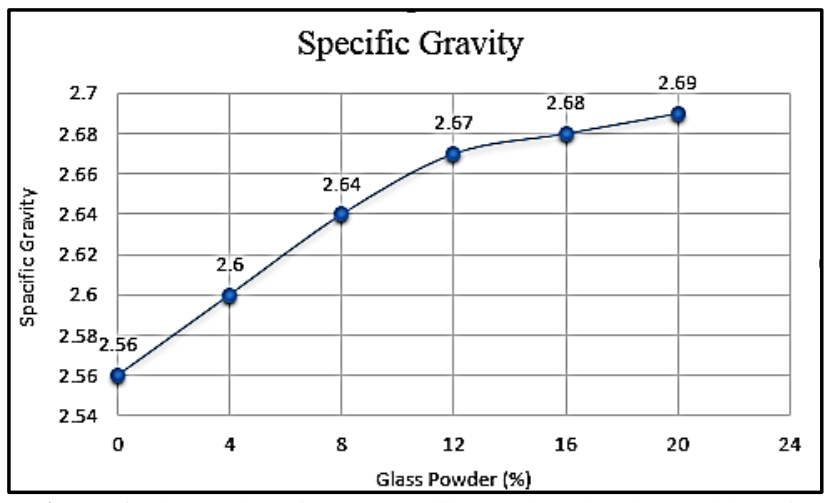

Figure 6: Fluctuation of Mass Specific Gravity with the Addition of WGP

\section{Effect on California Bearing Ratio}

To evaluate the subgrade strength for flexible pavements, it is necessary to determine the California Bearing Ratio (CBR). Moreover, CBR test results in calibration with some empirical curves give the required thickness in the design of flexible pavements. CBR design procedure is the most generally used method for pavements design. In this test, the penetration resistance of the subgrade materials was calculated. Figure 7 gives the entire variation of CBR on the addition of WGP.

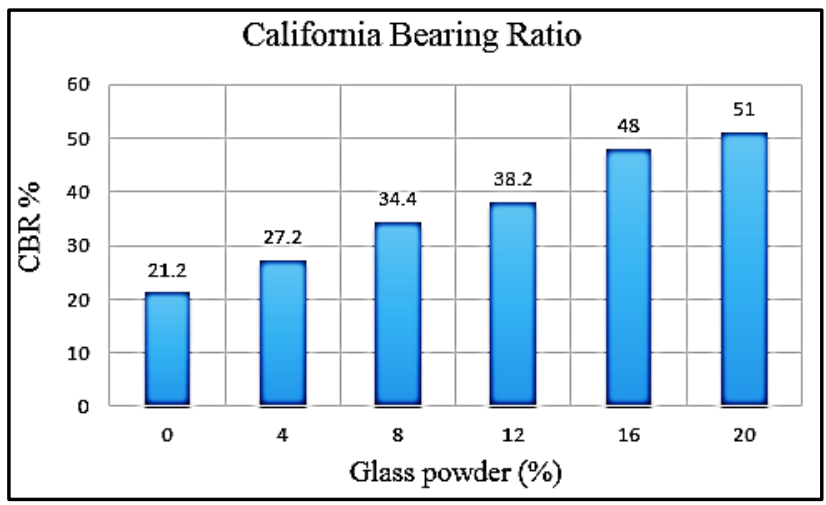

Figure 7: Fluctuation of CBR on the Addition of different Percentages of WGP

All the conducted tests were based on 2-inch penetration. The addition of WGP for the Karak expansive soil greatly improved the penetration resistance at all percentages. At 2-inch penetration, the glass powder contents hold the soil grains firmly which results from a greater CBR value. The CBR for controlled samples was found to be $21.2 \%$. WGP gradually increased the CBR value. It increased from this minimum value to a maximum of $51 \%$ at $20 \%$ addition of glass powder by weight. This increase in CBR is more than $50 \%$. Therefore, this locally produced WGP can be beneficially used in the stabilization of expansive soil, especially for pavements construction. As most of 
the roads passing on the expansive soil have been damaged due to settlement and heaved up in the Karak region.

\section{Effect on Liquid Limit}

The main characteristic of fine-grain soil is the liquid limit. The more liquid limit, the higher will be the swelling. The liquid limit of Karak expansive soil is greater than $50 \%$ making it high expansive clay. The liquid limit of Karak soil reduced from $51.5 \%$ to $36 \%$ after adding $20 \%$ of WGP as shown in Figure 8. The reduction in the liquid limit is mainly associated with the non-cohesive nature of WGP. Increasing the percentage of glass powder converting the mixture into frictiondominant material. The optimum glass content is $16 \%$ for the investigated expansive soil.

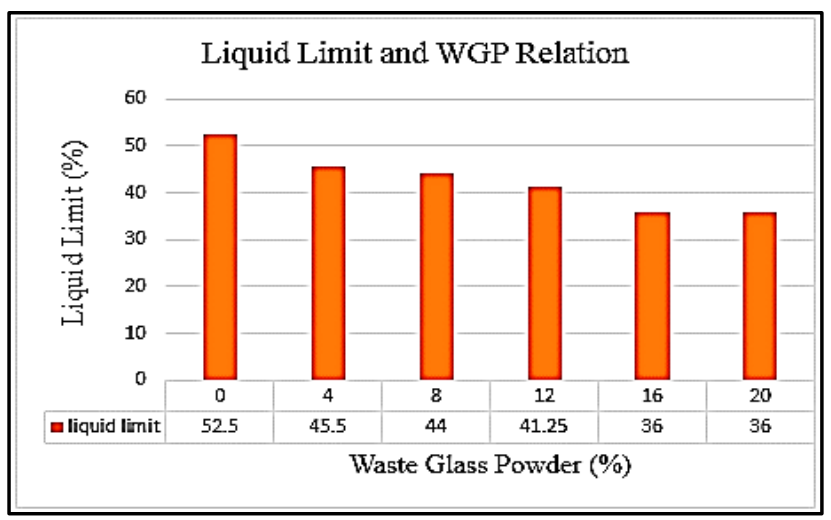

Figure 8: Reductions in the Liquid Limit Percentage due to the Addition of WGP

\section{E. Effect of WGP on the Swelling Behavior}

The swelling behavior was assessed by conducting the One-Dimensional (I-D) swelling tests under the guidelines of the ASTM D-4546 testing methodology. The maximum swelling was 2.0 percent for the controlled samples fabricated at zero percent of WGP. When WGP was added with the expansive soil, the 1-D swell potential was gradually reduced. The controlled samples expand about $2 \%$ of their original volume. The percentage of swell potential reduced to 1.43 at maximum addition of $20 \%$. As expansive soils contain minerals like montmorillonite, which is the major cause of expansion in the expansive soil. While the WGP contains silica, which is not expansive. Thus, the expansion capacity of the Karak soil is minimized because of the increased amount of silica content in the mixture. See Figure 9 below.

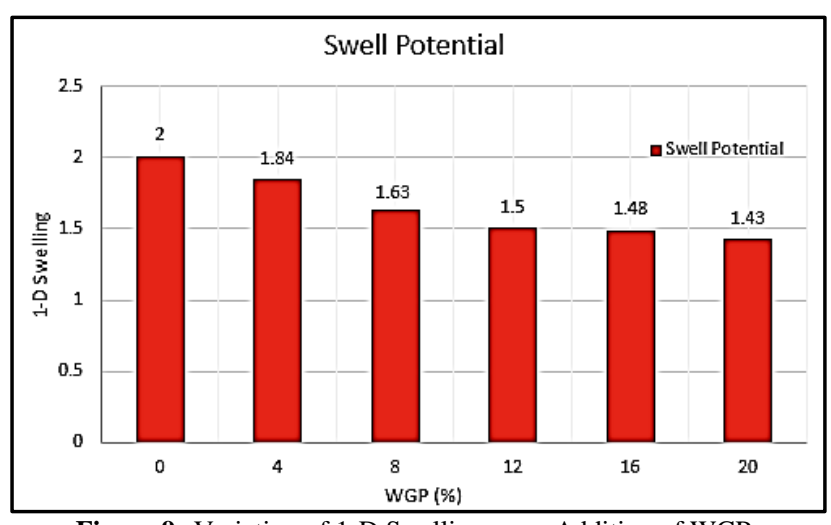

Figure 9: Variation of 1-D Swelling upon Addition of WGP
VII. SUMMARY OF THE INVESTIGATED PARAMETERS

The results of selected parameters that have been investigated and modified by the addition of WGP are summarized and listed in Table 2.

Table 2: Demonstration of the Overall Improvement Achieved in the Swelling and Strength Characteristics of Local Expansive Soils

\begin{tabular}{|l|c|c|c|}
\hline \multicolumn{1}{|c|}{ Properties } & $\begin{array}{c}\text { Initial } \\
\text { Values }\end{array}$ & WGP (\%) & $\begin{array}{c}\text { Modified } \\
\text { Values }\end{array}$ \\
\hline $\begin{array}{l}\text { Max. Dry Unit Weight } \\
{[\mathrm{kN} / \mathrm{m} 3]}\end{array}$ & 18.5 & 20.0 & 21.57 \\
\hline OMC [\%] & 17.8 & 20.0 & 13.50 \\
\hline Liquid Limit, [\%] & 52.5 & 16.0 & 36.0 \\
\hline CBR [\%] & 21.2 & 20.0 & 51.0 \\
\hline 1-D Swelling [\%] & 2.0 & 20.0 & 1.43 \\
\hline Specific Gravity & 2.56 & 20.0 & 2.69 \\
\hline
\end{tabular}

\section{CONCLUSION}

The experimental study was conducted to assess the impact of WGP produced by mechanical crushing of waste glasses on the geotechnical characteristics of Karak expansive soil. The addition of WGP in the expansive soil was previously limited to 10 percent. In the current investigation, the novel addition was extended to a maximum of 20 percent addition. The mixture of expansive soil and WGP at different percentages was tested with the help of intensive experimental work. Following are the major conclusions which are drawn from the results of this investigation:

It was concluded that the geotechnical properties including liquid limit, specific gravity, 1-D swelling, $\mathrm{CBR}$, and compaction characteristic can be improved by the addition of waste glass powder.

The glass powder has silica, which is a non-polar solid and causes a decrease in thickness of the water film around the dirt minerals since silica somewhat connects with mud minerals rather than water.

The behavior of investigated material showed a positive impact on the dry density and optimum moisture content of the investigated soil.

The addition of waste glass powder in the expansive subgrade soil will make the Karak expansive soil more suitable for the construction of flexible pavements.

The addition of glass powder for soil stabilization is one of the economical solutions for controlling the cyclic swell and shrink in the Karak expansive soil. This provides stabilization to the soil at the site of the development projects keeps away from the expenses of eliminating the soil as of now there and shipping new materials to the site.

The waste glass produced in Pakistan is discarded in open spaces near industrial zones. By recycling and utilizing this waste glass for soil stabilization purposes, the environment can be protected from harmful effects as well.

\section{RECOMMENDATIONS}

Based on the results, it is recommended to utilize the Waste Glass Powder or WGP, for the stabilization of 
weak soil for the construction of lightweight structures and pavements.

Some other industrial waste must be investigated in future studies for determining its applicability in the construction industry.

As the current investigation was focused on the swelling behavior along with some basic engineering properties. It is recommended to conduct a similar study focusing on the shrinkage of the expansive soils.

Similarly, the study is also recommended for future research on the different locations of the expansive soil of Pakistan.

\section{Acknowledgment}

I would like to acknowledge and give my warmest thanks to all the co-authors for their valuable inputs in making this work possible. The authors also appreciate the support of CECOS University of IT and Emerging Sciences, Peshawar Pakistan, in performing the experimental work of this study. Finally, the authors would like to thank God for letting them through all the difficulties.

\section{Authors Contribution}

The contribution of Dr. Bakht Zamin to this research work was the main idea, data collection, and paper writeup. Dr. Hassan Nasir play the role of project director and put this work in the right direction. Dr. Beenish Jehan and Dr. Asim Farooq helped in the experimental work of this study. Dr. M. Tariq Bashir performed data curation, set the methodology, and proofread.

\section{Conflict of Interest}

There is no conflict of interest between all the authors.

\section{Data Availability Statement}

The testing data is available in this paper.

\section{Funding}

This research received no external funding.

\section{References}

[1] Zamin, B., Nasir, H., Mehmood, K., Iqbal, Q., Farooq, A., \& Tufail, M. (2021). An Experimental Study on the Geotechnical, Mineralogical, and Swelling Behavior of KPK Expansive Soils. Advances in Civil Engineering, 2021.

[2] Seco, A., Ramírez, F., Miqueleiz, L., \& García, B. (2011). Stabilization of expansive soils for use in construction. Applied Clay Science, 51(3), 348-352.

[3] Buhler, R. L., \& Cerato, A. B. (2007). Stabilization of Oklahoma expansive soils using lime and class $\mathrm{C}$ fly ash. In Problematic soils and rocks and in situ characterization (pp. 1-10).

[4] Al-Rawas, A. A., Hago, A. W., \& Al-Sarmi, H. (2005). Effect of lime, cement and Sarooj (artificial pozzolan) on the swelling potential of an expansive soil from Oman. Building and Environment, 40(5), 681-687.

[5] Nalbantoğlu, Z. (2004). Effectiveness of class C fly ash as an expansive soil stabilizer. Construction and Building Materials, 18(6), 377-381.

[6] Aiban, S. A. (2006). Compressibility and swelling characteristics of Al-Khobar palygorskite, eastern Saudi Arabia. Engineering geology, 87(3-4), 205-219.

[7] Dash, S. K., \& Hussain, M. (2012). Lime stabilization of soils: reappraisal. Journal of materials in civil engineering, 24(6), 707714.
[8] Shahzada, K., Saeed, S., Ahmad, I., \& Khan, K. (2017). Stabilization of medium expansive soils in Pakistan using marble industrial waste and bagasse ash. International Journal of Earth Sciences and Engineering, 10(4), 885-891.

[9] Zamin, B., Nasir, H., Mehmood, K., \& Iqbal, Q. (2020). FieldObtained Soil-Water Characteristic Curves of KPK Expansive Soil and Their Prediction Correlations. Advances in Civil Engineering, 2020.

[10] Ene, E., \& Okagbue, C. (2009). Some basic geotechnical properties of expansive soil modified using pyroclastic dust. Engineering Geology, 107(1-2), 61-65.

[11] Katti, R., Kulkarni, U., Katti, A., \& Kulkarni, R. (2010). Stabilization of embankment on expansive soil-a case study. In Experimental and Applied Modeling of Unsaturated Soils (pp. 181-189).

[12] Puppala, A. J., Talluri, N., Congress, S. S. C., \& Gaily, A. (2018) Ettringite induced heaving in stabilized high sulfate soils. Innovative Infrastructure Solutions, 3(1), 1-12.

[13] Çimen, Ö., Keskin, S. N., \& Yıldırım, H. (2012). Prediction of swelling potential and pressure in compacted clay. Arabian Journal for Science and Engineering, 37(6), 1535-1546.

[14] Petry, T. M., \& Little, D. N. (2002). Review of stabilization of clays and expansive soils in pavements and lightly loaded structures-history, practice, and future. Journal of materials in civil engineering, 14(6), 447-460.

[15] Liaqat A., Z. Zulfiqar. (2011). Construction on expansive soils in a semi-arid zone. In Instrumentation, Testing, and Modeling of Soil and Rock Behavior, pp. 256-263. 2011.

[16] Öncü, Ş., \& Bilsel, H. (2018). Utilization of waste marble to enhance volume change and strength characteristics of sandstabilized expansive soil. Environmental earth sciences, 77(12), 113.

[17] Phani Kumar, B. R., \& Sharma, R. S. (2004). Effect of fly ash on engineering properties of expansive soils. Journal of Geotechnical and Geoenvironmental Engineering, 130(7), 764-767.

[18] Mujtaba, H., Farooq, K., Sivakugan, N., \& Das, B. M. (2013). Correlation between gradational parameters and compaction characteristics of sandy soils. International Journal of Geotechnical Engineering, 7(4), 395-401.

[19] Farooq, K. (1996). Engineering characteristics of expansive soils in pakistan (Doctoral dissertation, M. Sc. Thesis, University of Engineering and Technology, Lahore, Pakistan).

[20] Blayi, R. A., Sherwani, A. F. H., Ibrahim, H. H., Faraj, R. H., \& Daraei, A. (2020). Strength improvement of expansive soil by utilizing waste glass powder. Case Studies in Construction Materials, 13, e00427.

[21] Basha, E. A., Hashim, R., Mahmud, H. B., \& Muntohar, A. S. (2005). Stabilization of residual soil with rice husk ash and cement. Construction and building materials, 19(6), 448-453.

[22] Shamrani, M. A., Mutaz, E., Puppala, A. J., \& Dafalla, M. A. (2010). Characterization of problematic expansive soils from mineralogical and swell characterization studies. In GeoFlorida 2010: Advances in Analysis, Modeling \& Design (pp. 793-802).

[23] Akram, T., Memon, S. A., \& Obaid, H. (2009). Production of lowcost self-compacting concrete using bagasse ash. Construction and Building Materials, 23(2), 703-712.

[24] Chen, L., Du, Y. J., Liu, S. Y., \& Jin, F. (2011). Evaluation of cement hydration properties of cement-stabilized leadcontaminated soils using electrical resistivity measurement. Journal of Hazardous, Toxic, and Radioactive Waste, 15(4), 312320.

[25] Seda, J. H., Lee, J. C., \& Carraro, J. A. H. (2007). Beneficial use of waste tire rubber for swelling potential mitigation in expansive soils. In Soil improvement (pp. 1-9).

[26] Sharma, R. K., \& Bhardwaj, A. (2018, November). Effect of construction demolition and glass waste on stabilization of clayey soil. In International Conference on Sustainable Waste Management through Design (pp. 87-94). Springer, Cham.

[27] Cortellazzo, G., \& Cola, S. (2017). Geotechnical characteristics of two Italian peats stabilized with binders. In Dry mix methods for deep soil stabilization (pp. 93-100). Routledge. 
[28] Iqbal, S., Jehan, B., Khan, F. A., \& Nasir, H. (2018). Assessment of Engineering Properties of Artificial Aggregate Prepared From Canal Silt. Sir Syed University Research Journal of Engineering \& Technology, 8(II).

[29] Qamar, N., \& Khurram, A. A. (2018). 3 Tackling Demolition Waste-An en route to Sustainable Development. Sir Syed University Research Journal of Engineering \& Technology, 8(1), 8-8. 